\title{
Effect of Tempering on Microstructure and Mechanical Properties of Laser Welded and Post-Weld Treated AHSS Specimens
}

\author{
Farnoosh Forouzan ${ }^{1, a^{*},}$ Nanny Strandqvist ${ }^{1, b}$, Esa Vuorinen ${ }^{1, c}$, \\ Erik Navara ${ }^{2, d}$ and Frank Mücklich ${ }^{3, e}$
}

${ }^{1}$ Division of Materials Science, Luleå University of Technology, SE-97187 Luleå, Sweden

${ }^{2}$ Jihlava, Czech Republic

${ }^{3}$ Department for Materials Science, Functional Materials, Saarland University, D-66041 Saarbrücken, Germany

afarnoosh.forouzan@Itu.se, bnanstr-1@student.Itu.se, 'esa.vuorinen@ltu.se, deriknavara@gmail.com, ${ }^{\circ}$ muecke@matsci.uni-sb.de

Keywords: laser welding, quench and temper (Q\&T), dilatometer, hardness profile, tensile test.

\begin{abstract}
An advanced high strength steel $(0.08 \% \mathrm{C}, 1.79 \% \mathrm{Mn}, 0.23 \% \mathrm{Si})$ was subjected to different post-weld heat treatments by quenching \& tempering treatments (Q\&T) after laser welding to reduce the risk of martensite formation in a few seconds based on an idea of quench and partitioning (Q\&P), mechanism. The thermal stability of retained austenite, microstructure development and mechanical properties have been studied at 2 tempering temperatures of $440^{\circ} \mathrm{C}$ (Ms) and $636^{\circ} \mathrm{C}(\mathrm{Bs})$, both for 15 minutes, by means of electron microscopy, dilatometry, hardness profile and tensile tests. Dilatometer study unveiled that redistribution of carbon atoms and precipitation of transition carbides occur around $150^{\circ} \mathrm{C}$ and austenite decomposition occur at $600^{\circ} \mathrm{C}$. Tempering at $636^{\circ} \mathrm{C}$ resulted in notable effect on the mechanical properties, while no significant difference was detected at $440^{\circ} \mathrm{C}$, except a slight hardness drop. The strength increased up to $12 \%$ for the different specimens without significant loss in ductility for all specimens tempered at $636^{\circ} \mathrm{C}$, which may be caused by precipitation hardening and recrystallization of martensite lath boundaries during tempering around $600^{\circ} \mathrm{C}$.
\end{abstract}

\section{Introduction}

The need for steels to meet high yield strength $(>700 \mathrm{MPa})$ and acceptable elongation has grown during the past decades. This has led to development of Advanced High Strength Steels (AHSS). Though, welding of these materials without changing their mechanical properties is challenging especially after laser welding due to its high cooling rate, which can cause formation of martensite in the weld. Finding a post welding treatment which is fast and cheap is of vital interest [1-4]. Quenching and partitioning (Q\&P) is a fairly new thermal treatment method which was proposed by Speer et al.[5] with the aim to create a martensitic steel with high amount of retained austenite and to suppress the precipitation of cementite by adding enough $\mathrm{Si}$ or $\mathrm{Al}$ in the steel chemical composition. This mixed microstructure is said to provide a good combination between strength, ductility and toughness. The Q\&P process is divided into different stages. The procedure starts with quenching the steel from partial or total austenite state to a temperature between the martensite-start $\left(\mathrm{M}_{\mathrm{s}}\right)$ and martensite-final $\left(\mathrm{M}_{\mathrm{f}}\right)$ temperatures in order to form a controlled amount of martensite. The steel is thereafter held at the same temperature or heated to a temperature above or below $\mathrm{M}_{\mathrm{s}}$ for a specific time, this stage is called the partitioning stage and subsequently the steel is quenched to room temperature. Depending on volume fraction of martensite and austenite and the partitioning time, different microstructures can develop, e.g. retained austenite, martensite and bainite [6]. In this work, the idea behind Q\&P is used after laser welding of AHSS in order to control the microstructure and the mechanical properties of the weld and heat affected zone, by a very fast procedure. The first stage (Q1) creates a certain amount of martensite which increases the possible nucleation site-areas in the structure. During the reheating (T1) is therefore the nucleation of new phases is favored. The higher temperature favors also the growth of new phases and anneals the 
formed martensite. This provides a structure which does not contain large amounts of untempered martensite. The process enables a reduction of a normal post-weld heat treatment process from 30 minutes to less than one minute. But, since the chemical composition of this AHSS doesn't have high amount of silicon to slow down the retained austenite transformation, and to retard the carbide precipitation and provide the time for carbon partitioning to austenite during the first reheating (T1), we call this method quenching and tempering (Q\&T) in this manuscript. Since, we have 2 kinds of martensite, fresh and tempered respectively as a result of the Q\&T process, one much longer tempering stage has been added to this process (T2) (see Fig. 1).

Steels consisting of martensite are normally strong but brittle. So, tempering can be used to modify the mechanical properties. Martensite is highly supersaturated and strained by carbon atoms in the iron lattice. During tempering carbon atoms are rejected from martensite and will form carbides together with different elements and at these will be finely dispersed in the martensite. There are four temperature dependent stages during tempering [7,8].

Stage 1: The excess carbon segregate to lattice defects and form clusters which will precipitate as transition carbides, most in form of $\varepsilon$-iron carbides.

Stage 2: Retained austenite decomposes to other microconstituents, as bainite, ferrite and cementite. Stage 3: In this stage all carbon has been bonded to carbides and $\varepsilon$-iron carbides will dissolve and cementite carbides, $\mathrm{Fe}_{3} \mathrm{C}$ will be formed. Cementite has a Widmanstätten rod shape. Nucleation sites for cementite are probably at the interface between $\varepsilon$-iron carbides and the matrix, as cementite keeps growing $\varepsilon$-iron carbides gradually dissolve.

Stage 4: At high temperatures martensite lath boundaries starts to recrystallize and equi-axed ferrite grain boundaries are formed. The final result after this stage is therefore equi-axed array of ferrite grains with coarse and spheroidized cementite.

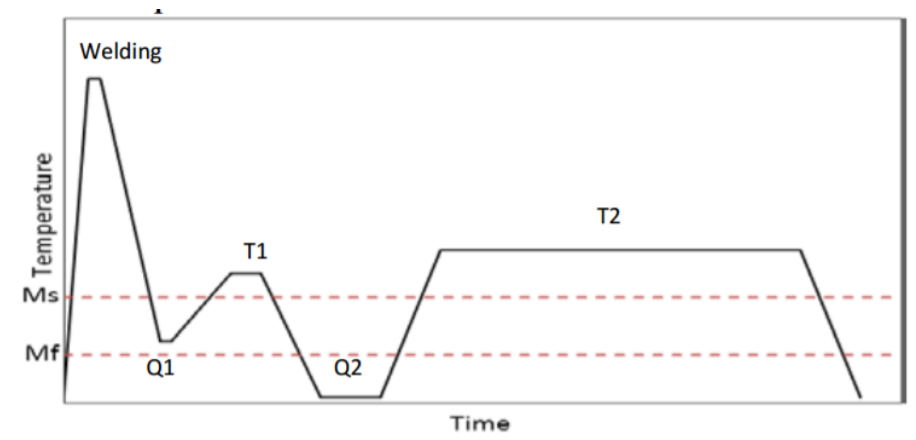

Fig. 1 Schematics of the process

Thermal stability of retained austenite, microstructure and properties of (Q\&P) treated AHSS in Sialloyed steels been investigated in some studies $[9,10]$. So, the objective of this work is to compare the characteristics of the FZ and HAZ after the second tempering stage with previous results and to investigate the effect of two different tempering temperatures $440^{\circ} \mathrm{C}$ (at Ms) and $636^{\circ} \mathrm{C}$ (at $\mathrm{Bs}$ ) on the stability of retained austenite, behavior of carbides precipitated during the first Q\&T part and mechanical properties of the weld area.

\section{Experimental procedure}

The steel used in this study was an AHSS, Domex 960 produced by SSAB Company for advanced lifting devices and lighter transport solutions and components. Chemical composition of the steel is presented in Table 1. The thickness of the steel sheets was $6 \mathrm{~mm}$.

Table 1 Chemical composition of Domex 960 (wt \%)

\begin{tabular}{ccccccccccccc}
\hline $\mathrm{C}$ & $\mathrm{Si}$ & $\mathrm{Mn}$ & $\mathrm{P}$ & $\mathrm{S}$ & $\mathrm{Al}$ & $\mathrm{Ti}$ & $\mathrm{Mo}$ & $\mathrm{Cr}$ & $\mathrm{Ni}$ & $\mathrm{Cu}$ & $\mathrm{V}$ & $\mathrm{N}$ \\
\hline 0.082 & 0.23 & 1.79 & 0.008 & 0.001 & 0.038 & 0.184 & 0.503 & 0.064 & 0.296 & 0.016 & 0.012 & 0.004 \\
\hline
\end{tabular}

Four different post-heat treated laser welded specimens were investigated in this project. The laser welded specimens were subjected to post-heat treatment by Q\&T process directly after the laser welding by using an induction coil above the sheet specimen. The four different Q\&T cycles can be seen in Table 2 below. 
Table 2 First part of quenching and tempering procedure for laser welded specimens

\begin{tabular}{llll}
\hline Weld no. & Quenching temp. (Q1 T) & Tempering temp.(T1T) & Holding time (T1t) \\
\hline 1 & $255^{\circ} \mathrm{C}$ & $640^{\circ} \mathrm{C}$ & :c \\
2 & $355^{\circ} \mathrm{C}$ & $540^{\circ} \mathrm{C}$ & :c \\
3 & $422^{\circ} \mathrm{C}$ & :c \\
4 & Room temp. & $540^{\circ} \mathrm{C}$ & :c \\
\hline
\end{tabular}

The laser welded specimens were tempered in a dilatometer in order to further investigate hardness and microstructure. Laser welded specimens No. 1 to 3 were cut to a size of $2.5 \times 0.5 \times 0.5 \mathrm{~cm}$. All specimens were heated in the dilatometer at constant rate of $3^{\circ} \mathrm{C} /$ minutes to $440^{\circ} \mathrm{C}$ and $636^{\circ} \mathrm{C}$ and held for 15 minutes and then cooled to room temperature. The thermocouple is measuring the temperature and the pushrod is holding the specimen at place with a force of $5[\mathrm{~N}]$ and measuring the change in length of the specimen.

Specimens for microstructure investigation were hot mounted and grinded by $\mathrm{SiC}$ abrasive papers with grit size from 240 to 2500 , polished with diamonds of $3 \mu \mathrm{m}, 1 \mu \mathrm{m}$ and $0.25 \mu \mathrm{m}$ size and finally with colloidal silica suspension. Samples were etched by Nital 3\% between 4 to 7 seconds. Optical microscopy (OM) was performed with Nikon eclipse MA20 and scanning electron microscopy (SEM) was done with Jeol IT-300.

Matsuzawa microhardness tester was used and the hardness was calculated by a program provided by JK-LAB. A load of $300 \mathrm{~g}$ was used in the measure of Vickers hardness profile for the specimens through the BM, HAZ and FZ, and indentation distances of about $0.3 \mathrm{~mm}$ was applied. Four tensile samples for all specimens were machined according to standard EN ISO 6892-1:2009. Regarding specimen No. 1 to 3 , two specimens tempered with the same procedure in a furnace and two samples were kept without tempering as reference for comparison of tempering on strength and elongation. The tensile tests were performed on Dartec tensile test machine.

\section{Result and discussion}

\section{Microstructural investigation}

Fig. 2(a) shows the entire weld area; base material, BM, heat affected zone, HAZ, and fusion zone (FZ). The FZ which is around $1 \mathrm{~mm}$ wide has large grains due to the melting and solidification and the HAZ area is approximately, $1 \mathrm{~mm}$ wide on each side of FZ. In Fig. $2 \mathrm{~b}$ the FZ can be seen on the right side and part of the HAZ is seen on left side. The martensite laths and blocks probably produced during the first quench can be recognized. Higher magnification reveals carbide precipitates in the structure (Fig. 3). Sample No.4, see Fig. 4, quenched to room temperature and tempered $5 \mathrm{sec}$ at $540^{\circ} \mathrm{C}$ shows much finer (approximately $100 \mathrm{~nm}$ ) precipitates all over the very fine martensitic structure of the sample in comparison to sample No.1 to 3 (see Fig. 3). In Fig. 3 we can see bainitic structure and a few larger carbide precipitates (approximately $250 \mathrm{~nm}$ ) just on the edges of thicker martensite lathes.
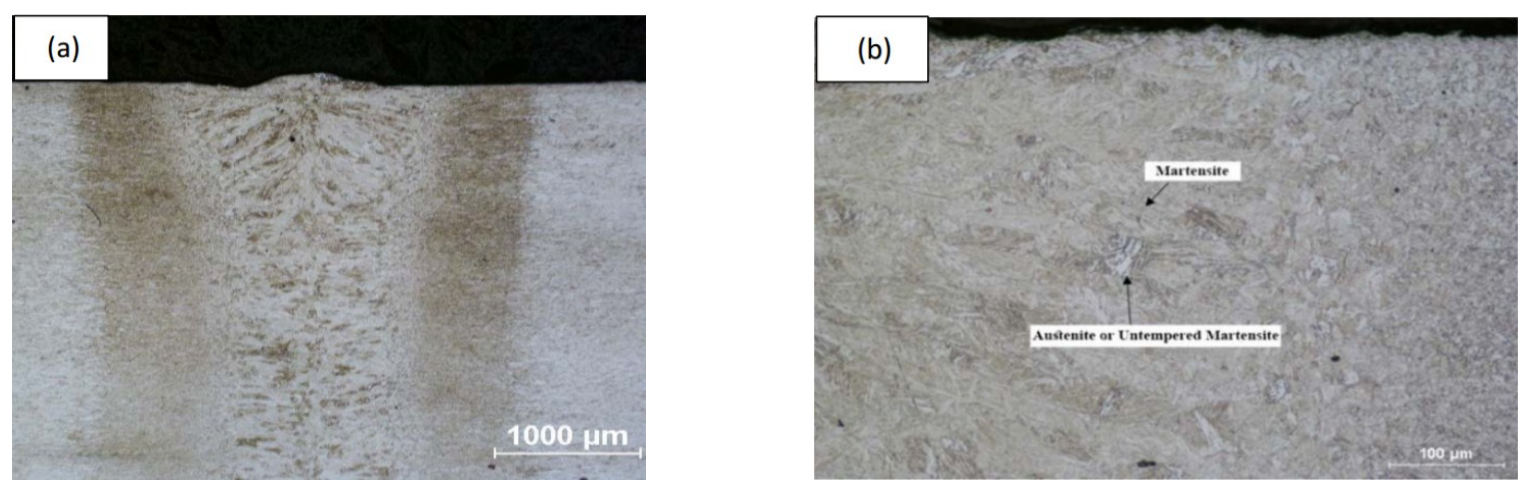

Fig. 2 Micrographs revealing morphology for specimen No. 1 tempered at $636^{\circ} \mathrm{C}$ (a) FZ, HAZ and BM (b) 

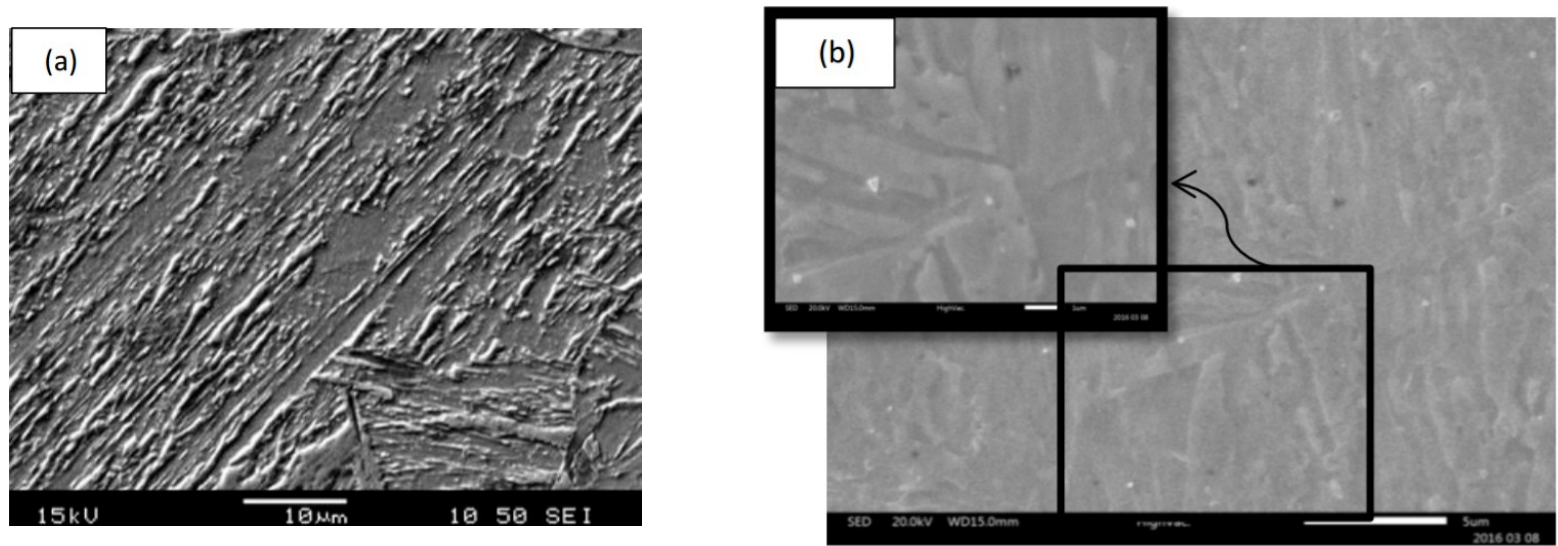

Fig. 3 SEM images of sample No.1,quenched to $255^{\circ} \mathrm{C}$, (a) First temper at $640^{\circ} \mathrm{C}$ for $2 \mathrm{sec}$ and (b) Second temper at $636^{\circ} \mathrm{C}$ for $15 \mathrm{~min}$

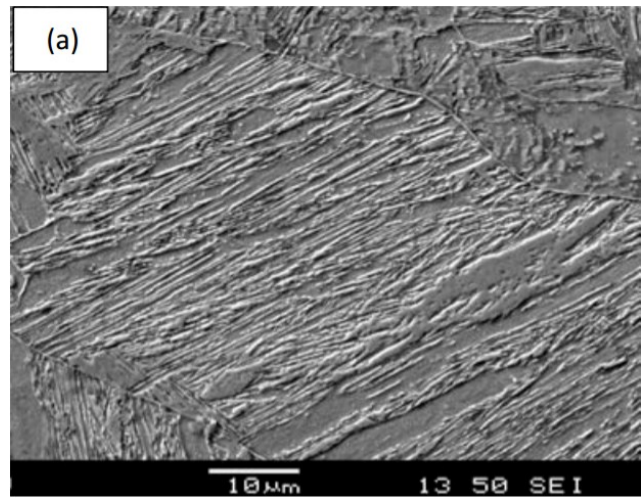

(b)

Fig. 4 SEM images of sample No.4 (a) Quenched to RT, (b) Quenched to RT and tempered at 540 for $5 \mathrm{sec}$

\section{Dilatometer study}

In order to find out what kind of transformations, could occur during tempering of Q\&T welds, dilatometer technique was used. As mentioned in the introduction, there are at least four stages of structural changes during tempering of martensite [8,11]. The curves seen in Fig. \& 6 are the derivative of the dilatometer change in length as a function of the temperature for specimen No. 1 to 3 heated to $440^{\circ} \mathrm{C}$ for 15 minutes. The first peak around $110^{\circ} \mathrm{C}$ backs to first stage of tempering in which carbon segregates to lattice defects and form clusters. Then around $150^{\circ} \mathrm{C}$, there is a small peak caused by the precipitation of transition carbides.

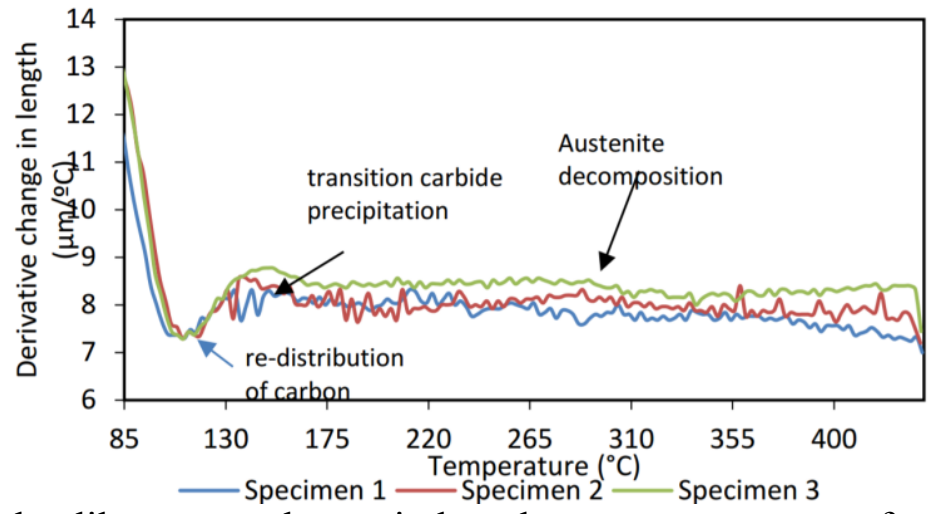

Fig. 5 Derivative of the dilatometer change in length versus temperature for specimen No. 1 to 3 heated to $440^{\circ} \mathrm{C}$

The volume fraction of retained austenite is not high, so the small peak around $300^{\circ} \mathrm{C}$ shows the decomposition of austenite to bainitic ferrite and cementite. No distinct peaks could be seen at higher temperatures although a temperature increase promotes growth of ferritic grains and cementite particles by Ostwald ripening mechanism as well as recovery process by elimination of 
low angle martensite interfaces and reduction of dislocation density. At $610^{\circ} \mathrm{C}$ precipitation of nitrides and/or carbides containing elements as ( $\mathrm{Ti}, \mathrm{Mo}, \mathrm{Mn}, \mathrm{Cr}$ ) occurs, by nucleation at preexisting cementite particles, or on the dislocations of the ferritic matrix, or at primary austenite grain boundaries and martensite lath boundaries [12].

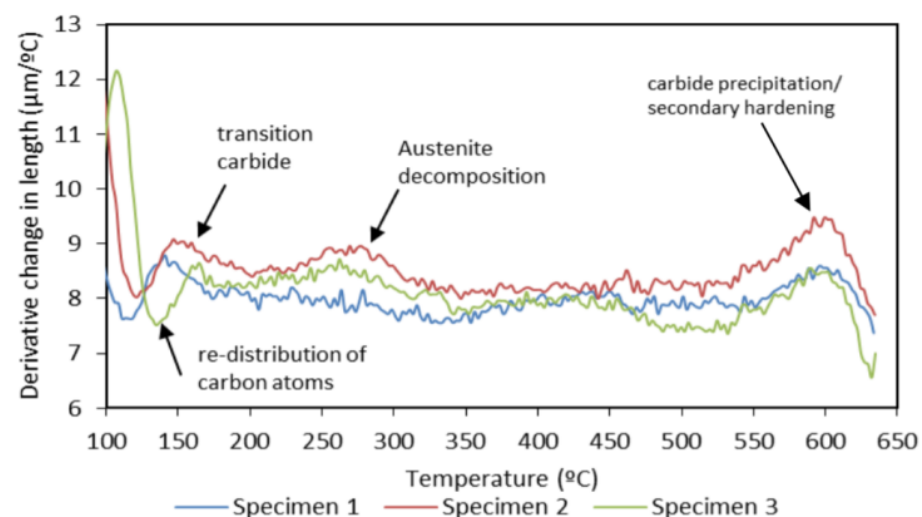

Fig. 6 Derivative of dilatometer change in length versus temperature for specimen No. 1 to 3 heated to $636^{\circ} \mathrm{C}$.

\section{Hardness profile}

In order to see how the hardness changes when the laser welded specimens were exposed to tempering, series of hardness measurements were performed across the weld area. All specimens No. 1 to 3 shows similar trend, specimen No. 2 is reported in Fig. 7. The hardness profile especially in the fusion zone, for specimens tempered at $636^{\circ} \mathrm{C}$ shows higher values compared to specimens tempered at $440^{\circ} \mathrm{C}$ and specimens without tempering. As explained by dilatometer study and SEM, decomposition of austenite, transformation of martensite (BCT) to ferrite (BCC) and nucleation of secondary precipitates at $610{ }^{\circ} \mathrm{C}$ are the main reasons for this difference between the hardness profiles. Regarding the classification of tempering behavior based on hardness changes as a function of tempering intensity, this behavior belongs to the class 4 . Very low carbon concentration of Domex 960, produces a lower as-quenched hardness but small amount of precipitation leads to secondary hardening $[13,14]$. This is also confirmed by Fig. 9 in the next section.

As shown in Fig. 7, the hardness is higher in the fusion zone in comparison with HAZ. This is what normally happens when steel is laser welded. The hardness in HAZ is lower compared to both the fusion zone and the base material due to longer tempering of the structure during laser welding and post weld heat treatments.

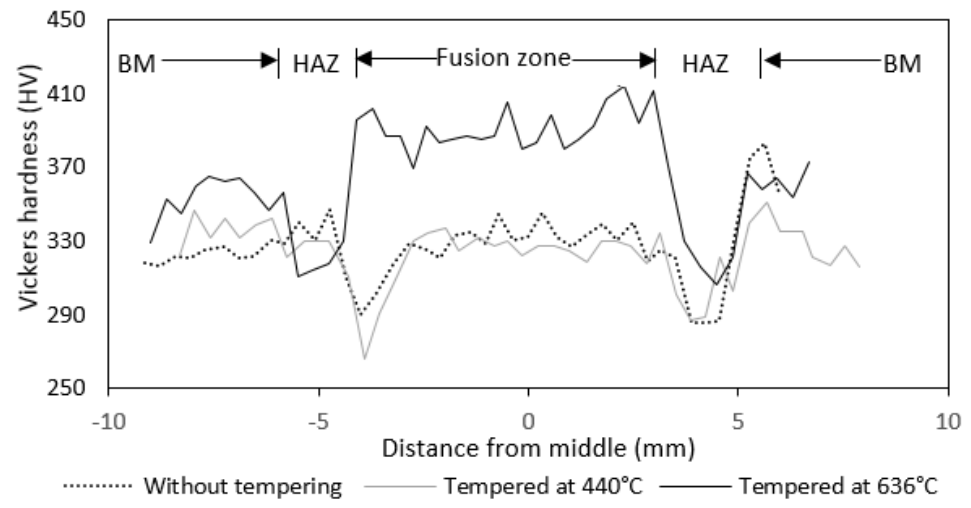

Fig. 7 Hardness profile of FZ, HAZ and part of BM for specimen No. 2

\section{Tensile test properties}

Two samples of each specimen from No.1 to 3 were tempered at $440^{\circ} \mathrm{C}$ and two were tempered at $636^{\circ} \mathrm{C}$ before tensile testing. One sample of each specimen was not subjected to tempering and tensile tested for comparison to examine the effect of tempering.

By analyzing all results (sample No.2 is shown in Fig. 8), it is clear that the yield strength and tensile strength values of the samples tempered at $440^{\circ} \mathrm{C}$ were not changed by the additional 
tempering stage. A slight increase of the elongation caused by stress relief by reduction of intracrystal dislocation density and softening of the second martensite created during the quenching to room temperature.

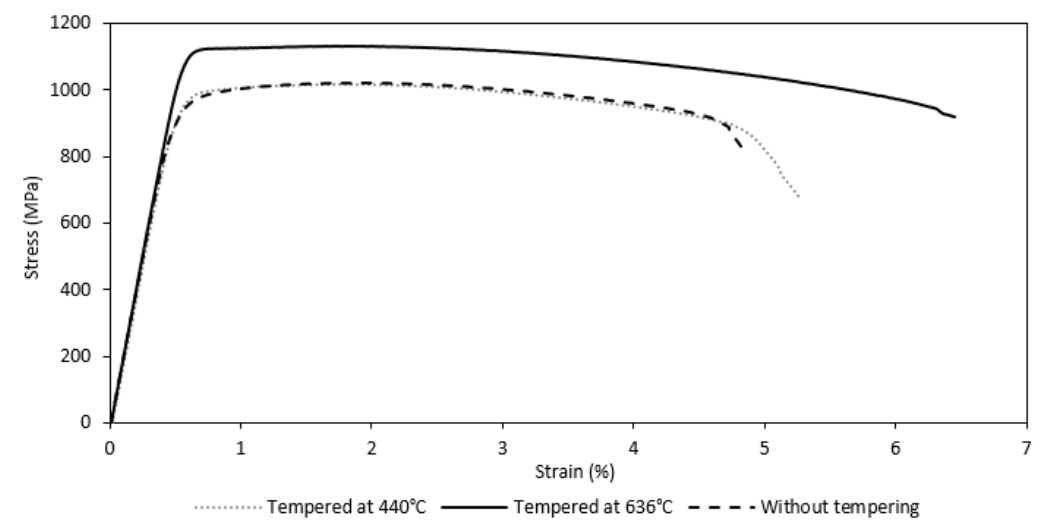

Fig. 8 Stress-strain curves for sample No.2; tempered at $636^{\circ} \mathrm{C}$, at $440^{\circ} \mathrm{C}$ and without tempering

In Fig. 9 it can also be seen that the yield strength and the tensile strength is higher for the specimen tempered at $636^{\circ} \mathrm{C}$ in comparison with specimens without tempering and specimens tempered at $440^{\circ} \mathrm{C}$. Zhu et al [15] showed the effect of different alloying elements on microstructural and mechanical properties at low temperature tempering. The results were discussed with respect to the effect of diffusivity of the substitutional alloying elements on maintaining fine distributions of cementite that resist softening during tempering at $300-400^{\circ} \mathrm{C}$. The results of tempering at $636^{\circ} \mathrm{C}$ shows that tensile strength increased up to $11.1 \%$ and yield strength up to $10.6 \%$, elongation shows also a rise of $32.9 \%$. Replacement of a coarse cementite dispersion by finer alloy carbides and/or nitrides, more resistant to coarsening and recrystallization of martensite lath boundaries to an equiaxed ferrite grain structure at around $600^{\circ} \mathrm{C}$ can produce an increase in both strength and elongation[16,17]. A comparison between all specimens at different tempering temperatures is shown in Fig. 9.

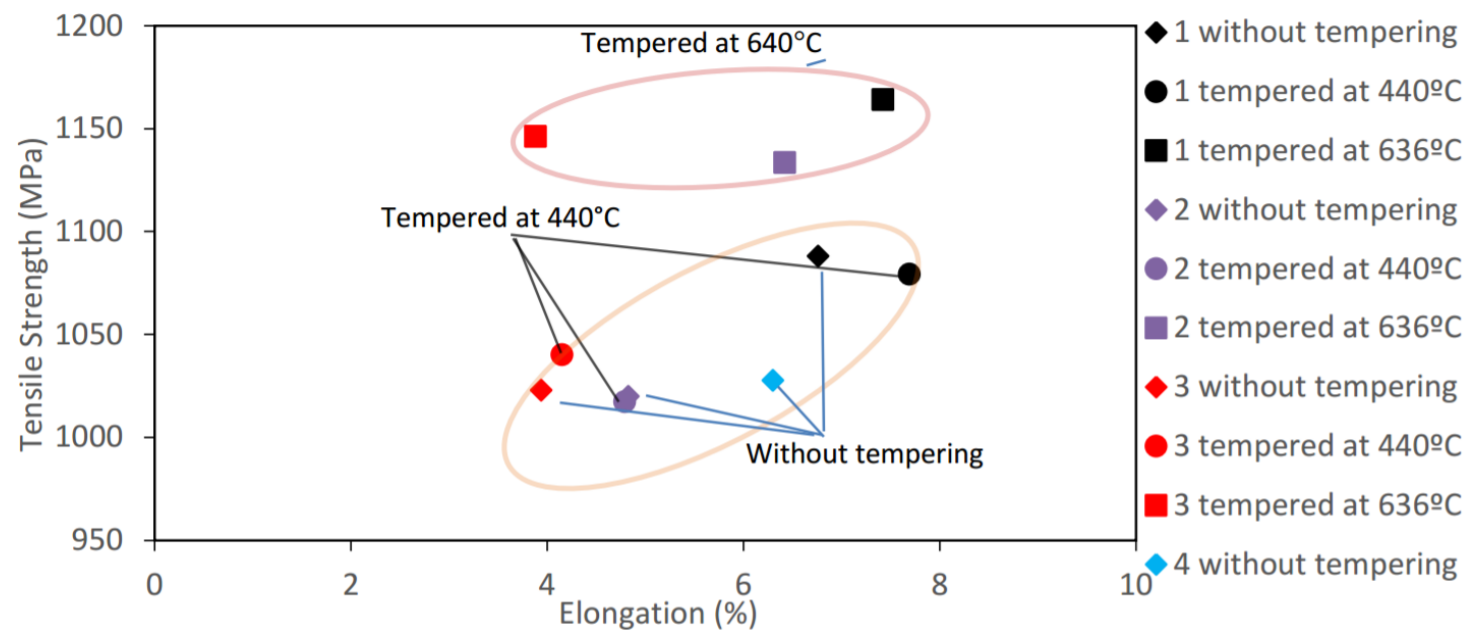

Fig. 9 Comparison between all specimens: without tempering, tempered at $440^{\circ} \mathrm{C}$ and tempered at $636^{\circ} \mathrm{C}$

\section{Conclusions}

Tempering of Q\&T treated steels indicates that redistribution of carbon atoms and precipitation of transition carbides occurs at approximately 110 and $150^{\circ} \mathrm{C}$ respectively. Then around $300^{\circ} \mathrm{C}$ decomposition of austenite to bainitic ferrite and cementite has been finished and increasing the tempering temperature promotes growth of ferritic grains and cementite particles by Ostwald ripening mechanism as well as recovery. Substitutional alloying elements resist softening during tempering at $300-400^{\circ} \mathrm{C}$, so the tensile test results of samples tempered to $440^{\circ} \mathrm{C}$ shows as high 
strength and slightly higher elongation than the untempered sample. Finally, around $610^{\circ} \mathrm{C}$, precipitation of carbides makes the strength increase of up to $12 \%$ with no loss in ductility.

\section{References}

[1] J. Pekkarinen, V. Kujanpää, The effects of laser welding parameters on the microstructure of ferritic and duplex stainless steels welds, Physics Procedia 5 Part A (2010) 517-523.

[2] M. Shome, M. Tumuluru, Welding and Joining of Advanced High Strength Steels (AHSS), Elsevier Science, 2015.

[3] N. Sreenivasan, M. Xia, S. Lawson, Y. Zhou, Effect of Laser Welding on Formability of DP980 steel, Journal of Engineering Materials and Technology 130 (2008) 041004-041004.

[4] E. Vuorinen, B. Bax, E. Navara, Weldability of hardenable silicon alloyed spring steel. Conference proceedings of Acta Metallurgica Slovaca Conference 14 (2010) 247-254.

[5] J. Speer, D.K. Matlock, B.C. De Cooman, J.G. Schroth, Carbon partitioning into austenite after martensite transformation, Acta Materialia 51 (2003) 2611-2622.

[6] M.J. Santofimia, L. Zhao, J. Sietsma, Overview of Mechanisms Involved During the Quenching and Partitioning Process in Steels, Metallurgical and Materials Transactions A 42 (2011) 36203626.

[7] G. Krauss, 5 - Tempering of martensite in carbon steels, in: E. Pereloma, D.V. Edmonds (Eds.), Phase Transformations in Steels, Woodhead Publishing, 2012, 126-150.

[8] L. Cheng, C.M. Brakman, B.M. Korevaar, E.J. Mittemeijer, The tempering of iron- carbon martensite; dilatometric and calorimetric analysis, Metallurgical Transactions A 19 (1988) 24152426.

[9] S. Zhou, K. Zhang, Y. Wang, J.F. Gu, Y.H. Rong, The Mechanism of High Strength-Ductility Steel Produced by a Novel Quenching-Partitioning-Tempering Process and the Mechanical Stability of Retained Austenite at Elevated Temperatures, Metallurgical and Materials Transactions A 43 (2012) 1026-1034.

[10] R.M. Wu, L. Wang, X.J. Jin, Thermal Stability of Austenite and Properties of Quenching \& Partitioning (Q\&P) Treated AHSS, Physics Procedia 50 (2013) 8-12.

[11] R.N. Caron, G. Krauss, The tempering of Fe-C lath martensite, Metallurgical Transactions 3 (1972) 2381-2389.

[12] H. Bhadeshia, R. Honeycombe, Steels: Microstructure and Properties: Microstructure and Properties, Butterworth-Heinemann, 2011.

[13] Front matter, in: E. Pereloma, D.V. Edmonds (Eds.), Phase Transformations in Steels, Woodhead Publishing, 2012, pp. i-iii.

[14] G.A. Roberts, R. Kennedy, G. Krauss, Tool Steels, ASM international, 1998.

[15] C. Zhu, X. Xiong, A. Cerezo, R. Hardwicke, G. Krauss, G.D.W. Smith, Three-dimensional atom probe characterization of alloy element partitioning in cementite during tempering of alloy steel, Ultramicroscopy 107 (2007) 808-812.

[16] D.A. Porter, K.E. Easterling, M. Sherif, Phase Transformations in Metals and Alloys, (Revised Reprint), CRC press, 2009.

[17] T. Tsuchiyama, M. Natori, N. Nakada, S. Takaki, Conditions for Grain Boundary Bulging during Tempering of Lath Martensite in Ultra-low Carbon Steel, ISIJ Int. 50 (2010) 771-773. 